\title{
On the way to stop infringement in intellectual property law and its improvement
}

\author{
Wenfeng $X U^{1, a}$ \\ ${ }^{1}$ Guangzhou Maritime University, Guangdong Province, Guangzhou City 510725, China \\ axuwenfeng@126.com
}

\begin{abstract}
Keywords: Intellectual property law; The way of stopping infringement relief; Improvement measures.

Abstract. intellectual property law as a branch of law, it is a kind of intellectual property protection in law, with the large scope of intellectual property rights in intellectual property law popularization, implementation and implementation have also been some difficulties, especially in the cessation of the infringement relief law. In the legislative and judicial level, there are many defects, which need further improvement and coordination, and adhere to the absolute and relative unity of dialectical point of view, the specific application specification will stop the infringement relief way clearly, so as to ensure the effective implementation of the law of intellectual property rights, to achieve good implementation effect. Based on the analysis of the current intellectual property law in the way to stop infringement relief and specific countermeasures to improve the analysis.
\end{abstract}

\section{Introduction}

In the current intellectual property law, the cessation of infringement is a traditional tort relief. With the advent of knowledge economy, intellectual property protection has become more complex and diverse, more and more ways to stop the infringement relief system of rules in nature, and this is the basic legal concept of justice and benefit to adapt. For the contradiction between the current legislation and social interests, the need for innovation and perfection of ceasing infringement, to make reasonable adjustments to the existing laws and regulations system, study the new architecture, to ensure the efficient implementation of intellectual property law.

\section{Analysis of the current legal system operating difficulties}

From the current legal system of our country operation situation, whether civil law or common law system, intellectual property rights have the same principle, the cessation of the Infringement Remedy but this principle is mostly abstract terms, the lack of specific, so it is difficult to obtain accurate set of criteria in actual judicial activities in. In addition, the principle of judicial application currently used in China is absolutely certain, in fact causes due to the special nature of the situation and make selective free judgment, the judge's purpose is to resolve the contradiction between legal provisions and social practice.

\subsection{The general and specific application of legislation}

From China's current civil legislation system, the right relief specification can be from the "civil law" in the "tort liability", "property law" in the protection of property rights "and" tort liability law "in the" liability and responsibility "in evidence. Whether civil law or intellectual property law, in the normative content of the cessation of infringement, the content of both is almost the same. First of all, the civil law system of our country briefly declared the cessation of the infringement in the law has the position, but in the concrete applicable scope is not very clear; secondly, the intellectual property rights of the private, exclusive and absolute nature of the right, to a great extent will draw some clauses in civil law from a system, however, to stop the infringement of intellectual property infringement is concerned, if in the simple and complicated traditional paradigm and normative content basis, it is difficult to find its unique functional requirements and system factor. 


\subsection{The trend of universal justice and autonomy}

In the "principles of the law of damages" referred to the "compensation for damages, indirect indirect relief, means more moderate; exclusion of infringement, as a result of direct attack against the means more intense". It is not difficult to see the cessation of the infringement as a legal means to combat IPR infringement, judicial practice is widespread adoption, as long as the implementation of intellectual property violations and intellectual property rights within the period of validity, the rights of people to obtain relief to stop the infringement is behoove, rarely have applied or limited application "stop violating the remedies of the judge, but at this stage the people's court did not make a clear judicial interpretation, however, there are still flexible applicable in practice, this kind of value orientation is to make judicial principle concessions to a certain extent in breaking the existing legislation under the restriction of freedom or quantitative, such as" product source the company of the Sun Farm Corporation patent infringement lawsuits ", finally basically is to" public interest "as the reason, refused to request the infringer to assume The corresponding civil liability, which breaks the traditional legal framework for the cessation of infringement. The court in the face of strong legal facts in front of the existing regulations or judicial discretion discretion, will cause a certain degree of conflict between the legislative system and the judicial path.

If the former is a kind of legal principle, the latter must be a kind of independent discretion". In the background of knowledge economy, the infringement of intellectual property relation is complicated and diversified, in specific cases, is to adhere to the law approved or "discretion" to achieve the realization of fairness and justice can become a problem, both problems are inevitable legal authority and unity, can said a law does not specify the behavior, whether to limit the scope of public welfare oriented private exercise, through the legislature to amend the regulations given cannot be accurately determined, the court decision in the case of a simple.

\section{Theoretical basis and thinking of the current regulatory system}

\subsection{The theory of real right of relief}

As a kind of civil rights, intellectual property rights are exclusive and exclusive. From the nature, the difference between intellectual property rights and intellectual property lies in the fact that it protects the intellectual property of intangible property. With the advent of knowledge economy, the value of knowledge information is more and more important. In order to ensure that it can become a wealth, in the legislation on the use of ownership law, in order to achieve the protection of intellectual property. The scholars believe that the tort law of common difficult to immediately stop the infringement behavior form the power of intellectual property ownership will give a similar "object" effect, so as to realize the purpose of protection of intellectual property rights, and this view of intellectual property rights relief judicial practice has an important influence on the court for approval, in tort the case when you need to adhere to the absolute right infringement claim principle. In addition, other scholars have also put forward their own point of view, the general intellectual property rights as an ordinary property rights and absolute rights to see, its exclusivity is also directly to the interpretation of the exclusive property rights.

\subsection{Relief system can form an independent system}

The contemporary theory of intellectual property rights is more emphasis on the differences between property rights and traditional property rights. The right to private ownership is subject to legal protection, but the protection of the laws and regulations corresponding to the types and categories of rights is not fixed. The right belongs to the scope of the property rules, and the relief method which is advocated after the violation belongs to the radiation scope of the liability rule. Property rules and liability rules are not immutable and frozen, both with different types of rights and the change in the law of real right, property rules can be understood as the property of "exclusive", and the liability rule 
can be understood as a form of tort, effectiveness of the "stop the infringement" and "exclusive" is the same in effectiveness, note that in the intellectual property law, this "exclusive" is incomplete and to be saturated, and the corresponding "stop violations" is not absolute effect of real right law.

Intellectual property is a new type of property rights, rights in the property rights system in many functions and can not be directly in the field of intellectual property in the application embodiment of ceasing infringement rights, the right to prohibit the kernel function and the reaction of the derivatives also have certain difference, in the right form of the difference will lead to intellectual property rights system and the ordinary civil system there is a big difference between the starting point and the ultimate goal, the ultimate goal of the intellectual property system more is the value of social welfare. In a word, the nature of the special power, the pursuit of value and the social purpose of the intellectual property system are the most important reasons for the cessation of the infringement.

\section{Analysis of the legislation of intellectual property system}

\subsection{Reference to foreign laws and regulations}

Intellectual property is a kind of respect for people to create wisdom, a protection, but in reality because it relates to the part of the public interests of the society makes the right will be restricted to a certain degree, and this is the main factor considered in the court to stop the infringement judgment when making.

In the United States, for the infringement of intellectual property of the appropriate policy restrictions, this restrictive policy is a long-term development and intellectual property rights system and the inherent laws of adjustment coincide, but this adjustment is also consistent with the scientific nature, for the future development of the intellectual property system will have a profound impact. For example, in one of the millions of words of books works, there are words of piracy, we need time to destroy the works, this is inconsistent with the seriousness of the infringement, but also damage to the interests of third parties, the public interest is damaged, from the Finisar Corp.v.DirecTV Group. case, the rational allocation of the final decision the court made not only difficult to achieve public resources, but also damage the public interests.

Restrictions on the use of the means to stop the infringement relief can also be seen in Italy. In Italy the right to file "Regulations of copyright law" in this aspect also has special instructions, such as the identity of the 169th litigation ", only in damage difficult to pass or supplement relief to the name of the author or other hidden announcement, party may request the exclusion of damage or destruction of infringing goods", article 170 "to protect the integrity of the work of the litigation expense, but only in the original form of the offender to recover work, can exclude or destroy the infringing material against the request".

\subsection{Innovation and perfection of domestic legislation system}

Based on the historical development of the intellectual property system traces shows that Eastern and Western cultures due to the reasons in legal tradition, legal culture, technology and other aspects of the legislation is in codification has some differences, but the problem of the legal protection of intellectual property rights in terms of eastern and Western countries in the formulation of regulations is not what obvious difference. This laid the foundation for intellectual property become an independent legal system and regulations. As for the present situation of our country's legal system, the premise of the improvement of the system of infringement relief is: first, the influence of the change of judicial policy on the legislation. In actual judicial practice, macro policy guidance and the impact is very obvious, the people's court to IPR judicial trial when it comes to the correct application of the civil liability system and puts forward some opinions, in accordance with the law applicable in the need to stop the infringement of civil liability, and the decision process violations still exist. The 
decision to immediately stop the infringement, for special infringement cases should be based on the actual situation of the interests of the measure, on the basis of full implementation of the comprehensive compensation or payment of economic compensation and other alternative, not determined to stop infringement behavior. Secondly, the changes in the practice of social justice has been widely recognized. To stop the infringement responsibility, do not need to conduct the subjective fault of that behavior as long as people appear regulations explicitly banned by tort, can make the decision to stop the infringement, preceded by the formation of a consensus gradually broken. With the progress of social development, uphold the principle of fairness and the social public interest has been widely recognized, the provisions of the regulations of the appropriate adjustments, and the public interest has become one of the most important reference factors to determine the responsibility of the cessation of the infringement ".

It is the basis of the existence and development of the intellectual property system to realize the protection of private legal rights and the balance of social public interests. Therefore, it is necessary to take into account the role of social public interest in legislation, which is an important component of the theory of balance of interests, and also the key to the arrangement of intellectual property rights. In addition, the intellectual property rights relief system also needs to reflect the "balance of interests" principle, therefore, the legislature is in to stop the infringement liability form applicable criteria are clear, focus on the analysis of basic set of "public interests". In legislation, our country in the formulation and revision of "patent law" late on account of this point, the "public interest" as a stop infringement applicable conditions of a limiting factor, however, changes in the laws and regulations in the late but the content of the terms deleted, so the legislature to stop infringement is lack of long-term understanding, and ultimately did not adhere to the restrictions on the stop infringement relief conditions in law. Through the above analysis, the legislative and judicial practice situation analysis, tort liability has a certain degree of flexibility in the specific commitment, the actual needs in real life can be based on the case, especially related to the social public interest factors, need to apply to stop the infringement relief law flexible.

\section{Summary}

Intellectual property rights as a document to protect the results of the creation of personal wisdom, with obvious exclusive and exclusive characteristics. In the actual infringement of intellectual property rights relief, the need for innovation to improve the existing legal system, make full use of foreign practices related to stop infringement rules, the absolute and relative coordinate a unified point of view, to further standardize the specific application will stop the infringement of the laws and regulations clearly, to improve, to meet the practical needs.

\section{Reference}

[1] Yang Tao. Reflection and improvement of the way of stopping infringement in intellectual property law [J]. intellectual property rights, 2014, (3): 79-84.

[2] Xu Qing. The limitation of the right of claim for infringement of intellectual property rights [D]. Huazhong University of Science and Technology, 2012

[3] Yang Tao. Claim right or tort liability: an analysis of the nature of "stop infringement" in intellectual property law [J]. intellectual property, 2015, (4): 95-100.

[4] Wang Shen. Stop patent infringement responsibility method applicable exception of [D]. Renmin University of China, 2012

[5] Li Yang, Xu Qing. The restriction of intellectual property rights on the right of claim of infringement [J]. jurist, 2012, 1 (6): 75-92. 
[6] He Huaiwen, Chen Ruwen. The legal principle of the restriction of the right of claim for intellectual property infringement in China [J]. Journal of Zhejiang University humanities and Social Sciences Edition, 2015, 45 (2): 133-150. 